\title{
Study on Hair Morphology to Distinguish the Dominant Races in Malaysia for Forensic Investigation
}

\author{
Nataraja Moorthy $\mathrm{T}^{*}$ and Jessica Marie Roy ${ }^{2}$ \\ ${ }^{1}$ Associate Professor of Forensic Sciences, Department of Medical Specialty, Faculty of Health and Life Sciences, \\ Management and Science University, Shah Alam, Selangor state, Malaysia \\ ${ }^{2}$ Forensic Science Program, Department of Medical Specialty, Faculty of Health and Life Sciences, Management and \\ Science University, Shah Alam, Selangor state, Malaysia
}

${ }^{*}$ Corresponding author: Nataraja Moorthy T, Associate Professor of Forensic Sciences, Department of Medical Specialty, Faculty of Health and Life Sciences, Management and Science University, Shah Alam, Selangor state, Malaysia, Fax: +0 0355108663, Tel: +6 0129224610, E-mail: natrajamoorthy@rediffmail.com Citation: Nataraja Moorthy T, Jessica Marie Roy (2015) Study on Hair Morphology to Distinguish the Dominant Races in Malaysia for Forensic Investigation. J Forensic Sci Criminol 3(4): 403. doi: 10.15744/23489804.3.403

\section{Received Date: June 02, 2015 Accepted Date: August 25, 2015 Published Date: August 28, 2015}

\begin{abstract}
Hair evidence is one of the most common types of evidence encountered in criminal investigations. The present preliminary study is aimed to investigate the racial discrimination through hair morphology viz. inner cuticle margin, cuticle thickness and medulla pattern among Malay, Chinese and Indian in Malaysia. Following standard procedure, a total of 180 volunteers' head hair samples, each 60 (30 males, 30 females) from consented Malay, Chinese and Indian, have been collected for analysis. Approximately $1 \mathrm{~cm}$ length of each hair was cut and suitably mounted using clean microscope slide, cover slide and mounting medium for analysis. The prepared hair slides were subjected to microscopic examination under different magnifications viz. 40X, 100X and 400X. The result of the hair investigation showed marked differences in hair morphology among the three races. The frequency and percentage of distribution of different hair morphology were tabulated and also presented in the form of bar graphs. This pilot study, the first of its kind in Malaysia provided a promising result in hair investigation showing racial discrimination among dominant races in Malaysia and the result of the investigation can be very well used in crime investigation.
\end{abstract}

Keywords: Forensic Science; Hair morphology; Hair comparison; Malay, Chinese and Indian; Malaysia

\section{Introduction}

Hair is commonly encountered in almost all criminal cases involving sexual offences etc. It may reveal information as species, race, sex and site of origin which is very useful from personal identification point. Hair has a distinct specialized anatomical structure. In forensic examination of hair, the morphological features which are primarily based on the detailed microscopic observations of the three components, namely cuticle, cortex and medulla, play a very important role [1]. The forensic anthropologist routinely compares the morphological characteristics of the hair samples in question to known hair samples to determine a transfer [2]. Most commonly, a comparison of the morphological characteristics of a known and unknown hair sample can be used to determine if they may have originated from the same source, although the microscopic characteristics of hair are not considered to be unique to individuals $[3,4]$. Attempts to discriminate human hair through chemical analysis has included monitoring hair dye components [5], hair oxidation [6], hair proteins [7,8], and trace elements [9,10]. Hair analysis is conducted at different levels as gross, microscopic and molecular based. In gross analysis, visual characteristics of hair are observed as color, length, texture and type. In microscopic analysis, more detailed hair characteristics are noticed that finally help to establish a correlation between a suspect and a crime scene or a suspect and a victim [11,12].

Malaysia has a complex multiracial population, predominantly defined by three major ethnic groups: Malay, 58\%; Chinese, 24\%; Indians, $8 \%$, and other groups, $10 \%$ with diverse cultural backgrounds [13]. The present investigation deals with the microscopic study of inner cuticle margin, cuticle thickness and the medulla pattern of the hair to distinguish the three dominant ethnic groups in Malaysia viz. Malays, Chinese and Indians.

\section{Materials and Methods}

A total of 180 volunteers' head hair samples, each 60 (30 males, 30 females) from consented Malay, Chinese and Indian, were extracted following the procedure for analysis and the percentage of sample size is shown in Figure 1. Approximately 20 hairs per individual were collected. The subjects were requested to sit in a relaxed position and samples were extracted from different areas of head using tweezers and packed the collected samples in separate envelopes. All hair samples and information relating to partic- 


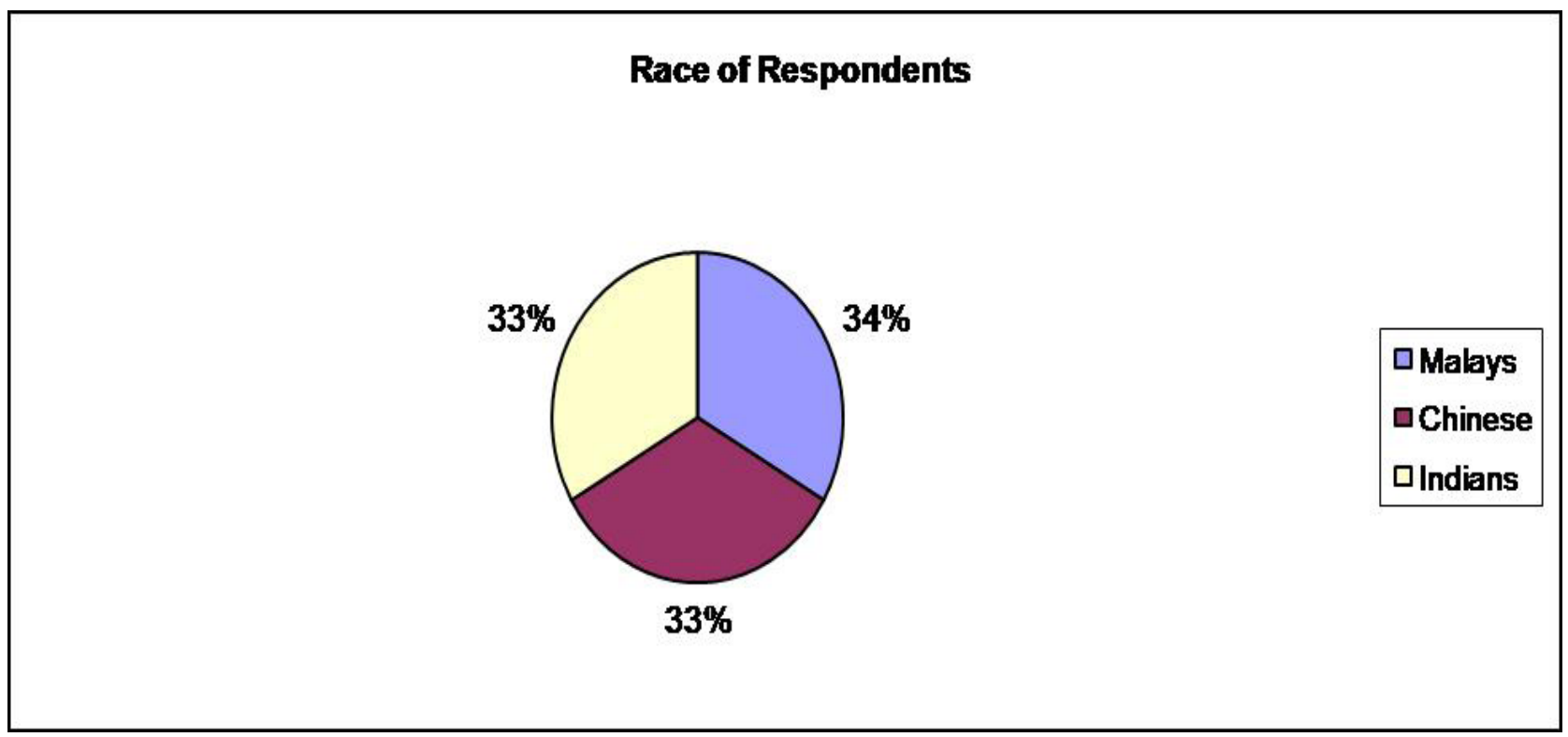

Figure 1: Sample size proportion of races under study

ipants were coded with a sample ID for anonymity. Following Amna Khan, et al, some strands of distal end of hair were placed on slide in parallel fashion. Then few drops of transparent were dropped on cover slip and it was placed over the slide to fix the hairs. The prepared hair slides were examined through stereo microscope (Labomed, model CxL) under appropriate magnifications viz. 40X, 100X and 400X and recorded with photography. The procured data were compiled, organized and analyzed statistically. The descriptive results of inner cuticle margin, cuticle thickness and medulla pattern of the hairs are presented as tables and bar graphs using frequency and percentage.

\section{Results}

The following results were obtained based on the hair analysis of the three parameters viz. cuticle thickness, inner cuticle margin and medulla pattern.

\section{Inner cuticle margin}

The inner cuticle margin refers to the apparent border between the cortex and the visible cuticle. The variates of the inner cuticle margin consist of distinct, indistinct and varied as viewed longitudinally [14] and the three categories are shown in Figure 2. The result showed that in Malay males, twenty five samples were distinct, three were indistinct and only two were as varied. On the contrary, the male Chinese and Indian samples showed similar number of distinct, indistinct and varied inner cuticle margin. The examination of female hair showed variation among the races. The frequencies and percentage distributions are shown in Table 1 and Figure 3.

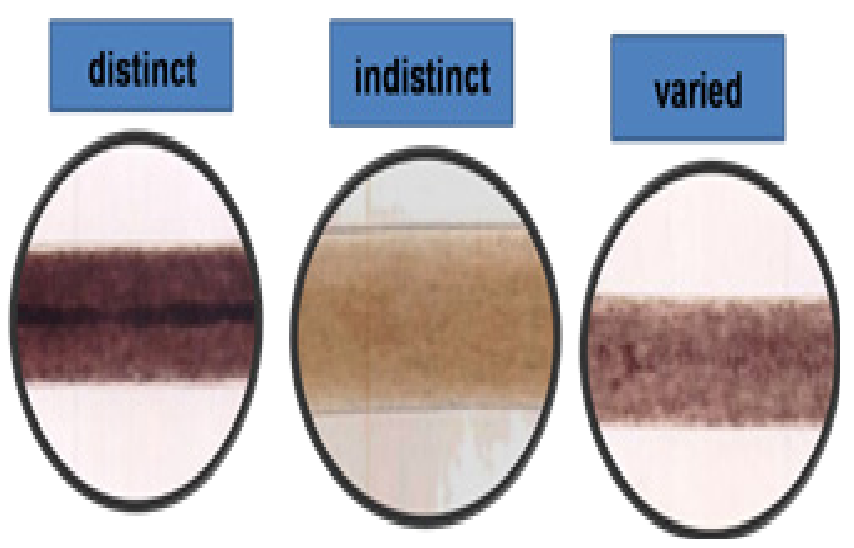

Figure 2: Inner cuticle margin showing the different categories 


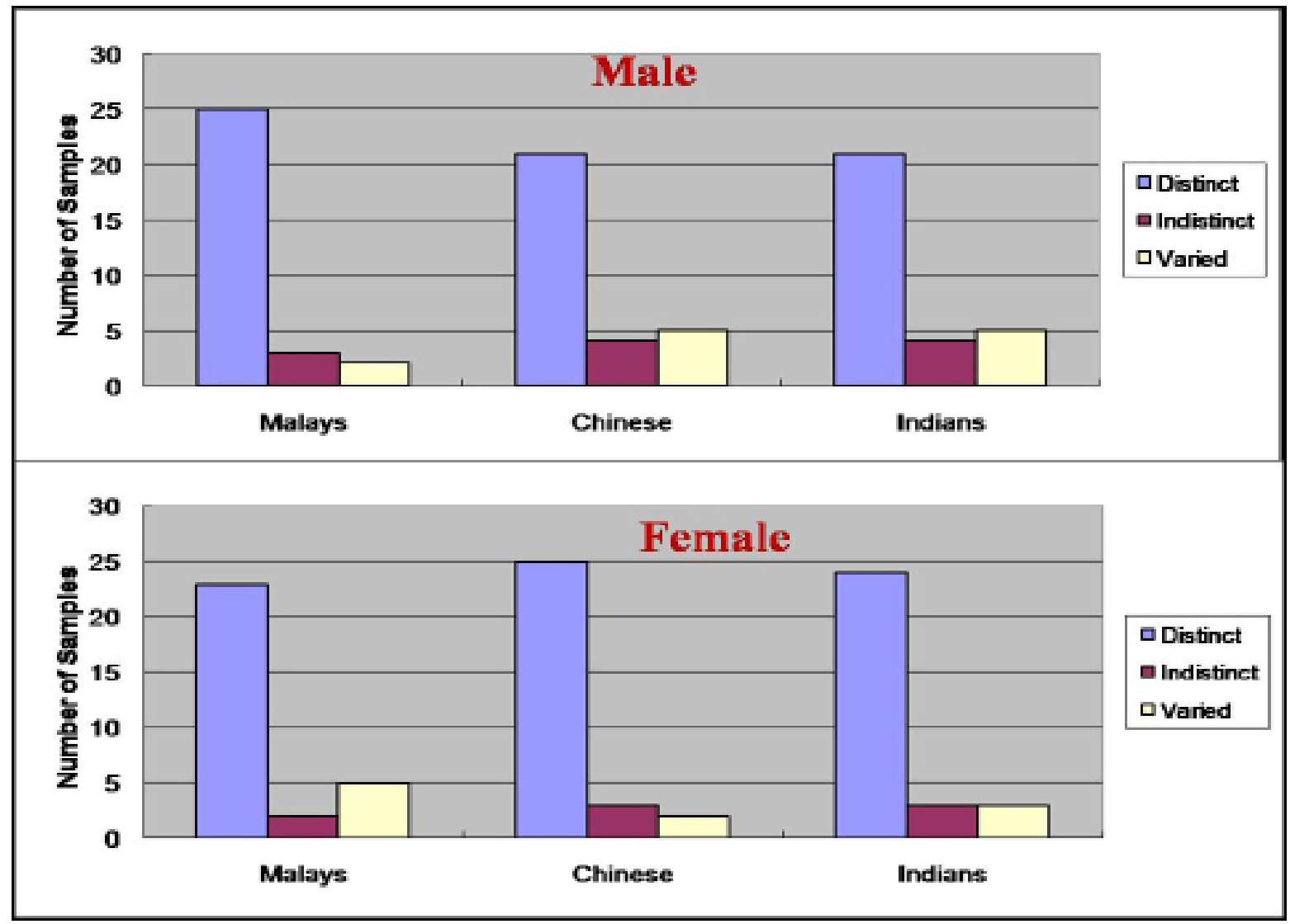

Figure 3: Bar graph showing inner cuticle margin in males and females among the races

\begin{tabular}{|c|c|c|c|c|c|c|c|c|c|c|c|c|}
\hline \multirow{3}{*}{$\begin{array}{l}\text { INNER } \\
\text { CUTICLE } \\
\text { MARGIN }\end{array}$} & \multicolumn{4}{|c|}{ MALAY } & \multicolumn{4}{|c|}{ CHINESE } & \multicolumn{4}{|c|}{ INDIAN } \\
\hline & \multicolumn{2}{|c|}{ MALE } & \multicolumn{2}{|c|}{ FEMALE } & \multicolumn{2}{|c|}{ MALE } & \multicolumn{2}{|c|}{ FEMALE } & \multicolumn{2}{|c|}{ MALE } & \multicolumn{2}{|c|}{ FEMALE } \\
\hline & $\mathbf{n}$ & $\%$ & n & $\%$ & $\mathbf{n}$ & $\%$ & $\mathbf{n}$ & $\%$ & $\mathbf{n}$ & $\%$ & $\mathbf{n}$ & $\%$ \\
\hline Distinct & 25 & 41.7 & 23 & 38.3 & 21 & 35.0 & 25 & 41.7 & 21 & 35.0 & 24 & 40.0 \\
\hline Indistinct & 3 & 5.0 & 2 & 3.3 & 4 & 6.7 & 3 & 5.0 & 4 & 6.7 & 3 & 5.0 \\
\hline Varied & 2 & 3.3 & 5 & 8.3 & 5 & 8.3 & 2 & 3.3 & 5 & 8.3 & 3 & 5.0 \\
\hline
\end{tabular}

Table 1: Frequency and percentage distributions of distinct, indistinct and varied types observed in the inner cuticle margin among the races

\section{Cuticle thickness}

The variates of cuticle thickness are thin and thick [14] and shown in Figure 4. The result of thick cuticles in males showed that the frequency is found to be more often in Chinese (41.3\%) followed by Malays (33.3\%) and Indians (15.5\%). Similar sequence is observed in females also, namely the frequency of cuticle thickness is comparatively more in Chinese (47.8\%) followed by Malays (35.4\%) and least in Indians (20\%). Whereas the result of thin cuticle in males showed that the frequency is found to be more often in Indians viz. fourteen, followed by nine in Malays and two in Chinese. Similar sequence is observed in females, having higher frequency in Indians viz fifteen, followed by six in Malays and least three in Chinese. Hence the result of thin cuticle showed that the frequency and sequence is same in both the genders whereas thick cuticle showed variation in sequence and frequency among genders. The frequencies of thin and thick cuticles are shown in Figure 5 and Table 2.

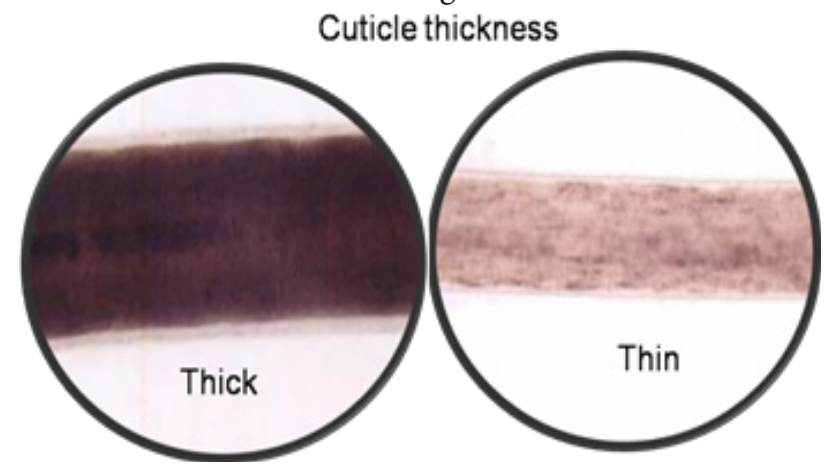

Figure 4: Hairs showing thin and thick cuticle 


\begin{tabular}{|c|c|c|c|c|c|c|c|c|c|c|c|c|}
\hline \multirow{3}{*}{$\begin{array}{l}\text { CUTICLE Race } \\
\text { THICKNESS }\end{array}$} & \multicolumn{4}{|c|}{ MALAY } & \multicolumn{4}{|c|}{ CHINESE } & \multicolumn{4}{|c|}{ INDIAN } \\
\hline & \multicolumn{2}{|c|}{ MALE } & \multicolumn{2}{|c|}{ FEMALE } & \multicolumn{2}{|c|}{ MALE } & \multicolumn{2}{|c|}{ FEMALE } & \multicolumn{2}{|c|}{ MALE } & \multicolumn{2}{|c|}{ FEMALE } \\
\hline & $\mathbf{n}$ & $\%$ & n & $\%$ & $\mathbf{n}$ & $\%$ & $\mathbf{n}$ & $\%$ & n & $\%$ & $\mathbf{n}$ & $\%$ \\
\hline Thick & 16 & 33.3 & 17 & 35.4 & 19 & 41.3 & 22 & 47.8 & 7 & 15.5 & 9 & 20.0 \\
\hline Thin & 9 & 18.7 & 6 & 12.5 & 2 & 4.3 & 3 & 6.5 & 14 & 31.1 & 15 & 33.3 \\
\hline
\end{tabular}

Table 2: Frequency and percentage distributions of thin and thick cuticle among three races

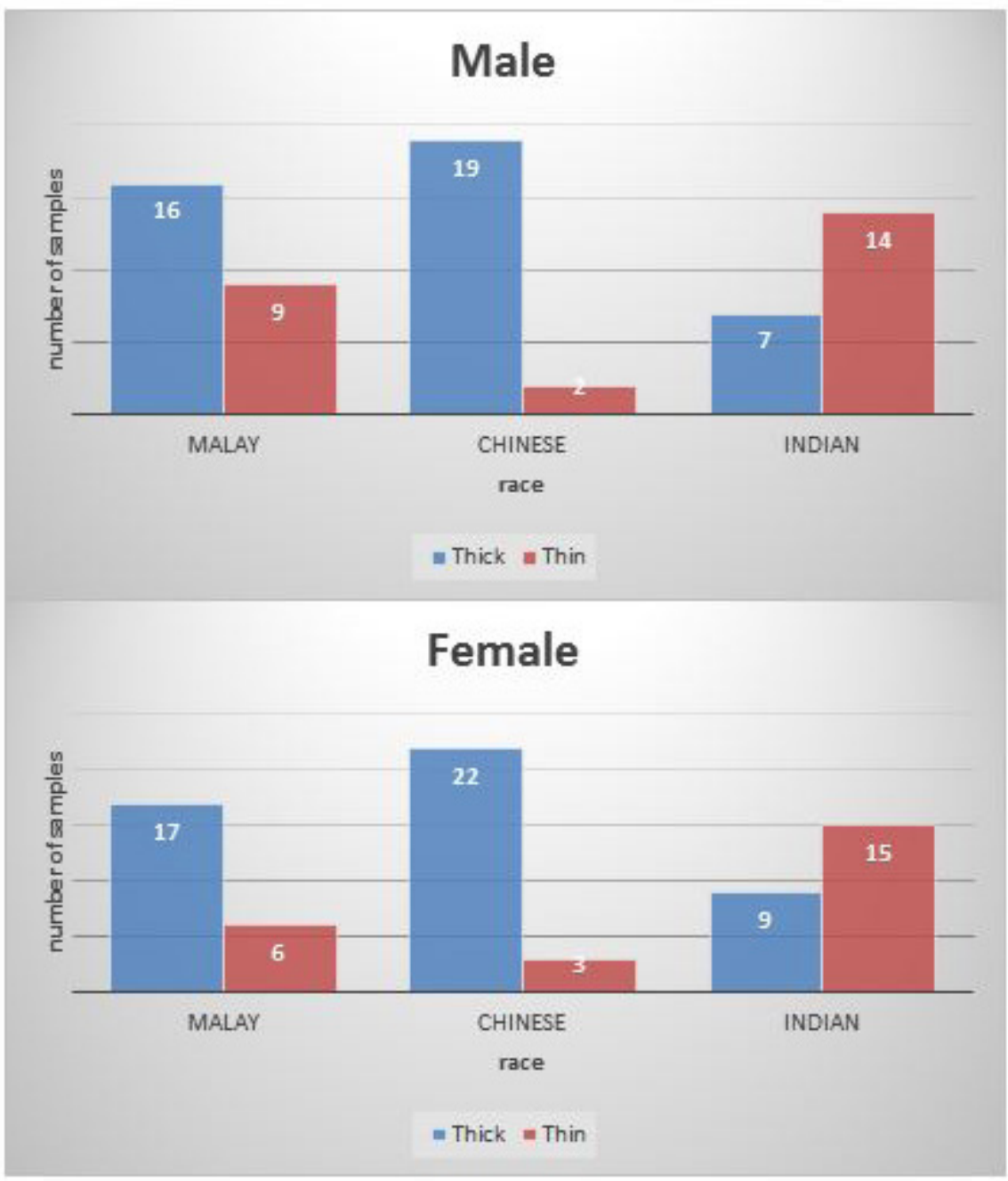

Figure 5: Distribution of thick and thin cuticles in hairs among gender and races

\section{Medulla patterns}

The central or innermost core of the hair, the medulla contains a collection of cells but appears as if it's an empty or mud-filled central canal. In human hairs, the medulla is generally amorphous in appearance. The medulla's appearance can be typed as continuous, fragmental and absent. The different types of medulla pattern are shown in Figure 6.

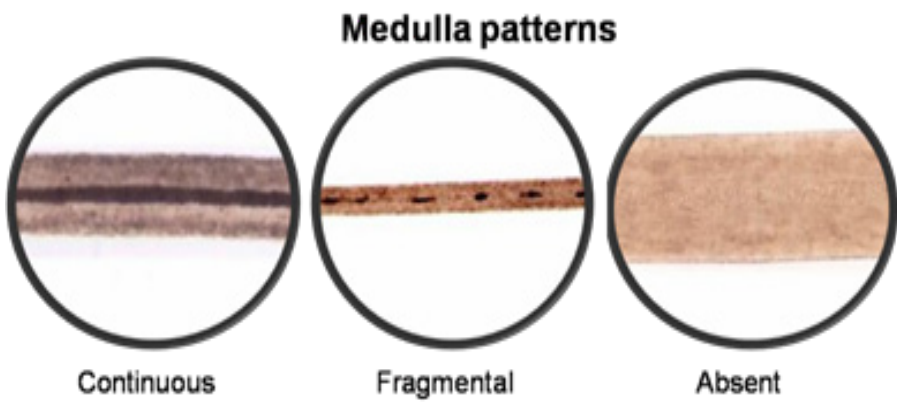

Figure 6: Types of medulla pattern 
The sequence of continuous medulla pattern in males is found be in the order of twenty five in Malays followed by ten in Chinese and eight in Indians whereas in females, the sequence is found to be in the order of twenty four in Malays followed by eleven in Indians and nine in Chinese. Whereas the sequence of fragmented pattern in both gender is in the order of Chinese followed by Indian and Malays. The absent pattern did not show significant variation among the races. The frequency and percentage distribution of these three patterns are shown in Table 3 and Figure 7.

The sequence of fragmented medulla pattern in males is found be in the order of eighteen in Chinese followed by seventeen in Indians and three in Malays whereas in females, Indians and Chinese showed similar frequencies viz. seventeen and two in Malays. The absent pattern did not show significant variation among the races. The frequency and percentage distribution of these three patterns are shown in Table 3 and Figure 7.

\begin{tabular}{|c|c|c|c|c|c|c|c|c|c|c|c|c|}
\hline \multirow{3}{*}{$\begin{array}{l}\text { MEDULLA Race } \\
\text { PATTERN }\end{array}$} & \multicolumn{4}{|c|}{ MALAY } & \multicolumn{4}{|c|}{ CHINESE } & \multicolumn{4}{|c|}{ INDIAN } \\
\hline & \multicolumn{2}{|c|}{ MALE } & \multicolumn{2}{|c|}{ FEMALE } & \multicolumn{2}{|c|}{ MALE } & \multicolumn{2}{|c|}{ FEMALE } & \multicolumn{2}{|c|}{ MALE } & \multicolumn{2}{|c|}{ FEMALE } \\
\hline & $\mathbf{n}$ & $\%$ & n & $\%$ & $\mathbf{n}$ & $\%$ & $\mathbf{n}$ & $\%$ & n & $\%$ & $\mathrm{n}$ & $\%$ \\
\hline Continuous & 25 & 41.7 & 24 & 40.0 & 10 & 16.7 & 9 & 15.0 & 8 & 13.3 & 11 & 18.3 \\
\hline Fragmented & 3 & 5.0 & 2 & 3.3 & 18 & 30.0 & 17 & 28.3 & 17 & 28.3 & 17 & 28.3 \\
\hline Absent & 2 & 3.3 & 4. & 6.7 & 2 & 3.3 & 4 & 6.7 & 5 & 8.3 & 2 & 3.3 \\
\hline
\end{tabular}

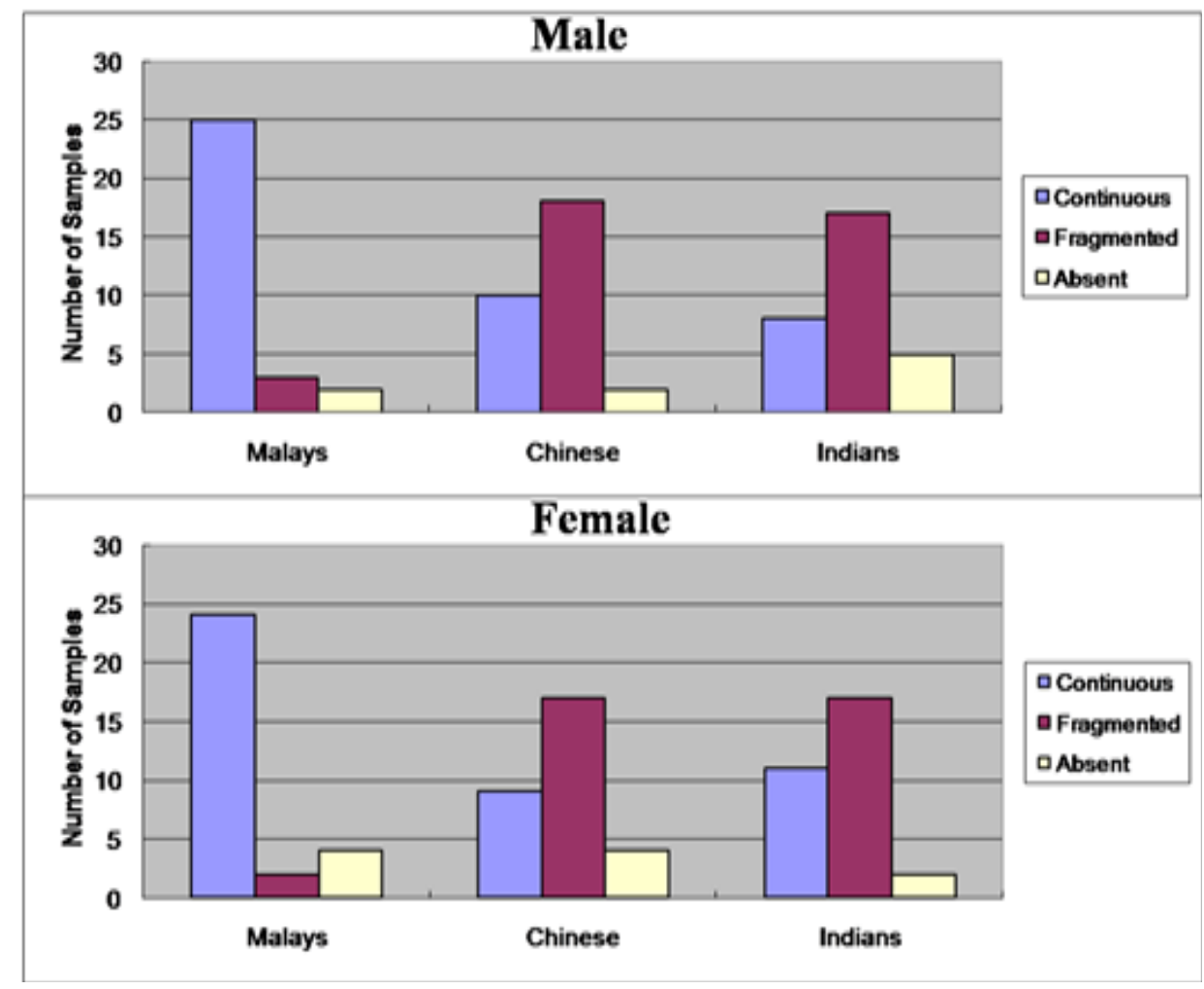

Figure 7: Distribution of hair medulla pattern in hairs of males and females among the races

\section{Discussion}

Malaysia is a multi-racial, multi-cultural and multi-religion country with a rich cultural heritage. Malaysia has about 28 million people, made-up of three main ethnic groups of Malays (58\%), Chinese (24\%), Indians (8\%) and other minorities (10\%). Hair is an important trace evidence commonly encountered in almost all criminal cases mostly involving sexual offences. It may reveal information as species, race, sex and site of origin which is very useful from personal identification point [1]. This trace evidence can be used for the purposes of eliminating individuals from police enquiries as well as to help narrow down the list of suspects. The discovery of hair on the body of a victim or on the clothes of someone who has been the victim of an assault can often be used to determine race and gender. The result of the inner cuticle margin and cuticle thickness shows variation among the races. Similar comparative study on cuticle structure was conducted on Asian and Caucasian hairs and showed variation that can be used in forensic investigation [15]. The present investigation on medulla pattern frequency distribution among Malays, Chinese and Indians showed positive result to discriminate the three races which can be used as corroborative evidence in real crime scenarios. The findings of this study are suggestive of medulla pattern and support the views expressed in hair research work conducted among four different castes in Pakistan [16]. The present study showed gender difference through medulla pattern and the finding is in accordance with the findings in Indian population studies conducted by O.P. Jasuja [1] and Kaur [17]. 


\section{Conclusion}

This pilot study, the first of kinds in Malaysia highlights the morphological differences in hairs among the major races viz. Malays, Chinese and Indians. The result of the study can be used to narrow down the suspects in crime scene investigation. Therefore the researchers are encouraged to conduct similar studies for different ethnic groups living in different parts of the world so that the genetic and environmental effects can be investigated in forensic terms.

\section{References}

1. Jasuja OP, Minakshi (2002) A study of variations in some morphological features of human hair. J Punjab Acad Forensic Med Tox 2: 1-6.

2. Sen J (2010) Human hair in personal Identification and documenting drug and substance abuse. Anthropologist 12: 47-58.

3. Saferstein R (1990) Criminalistics: an introduction to forensic science. 4th ed. Englewood Cliffs: Prentice-Hall, Inc.

4. Bisbing RE (1982) The forensic identification and association of human hair. In: Saferstein R. Forensic Science Handbook, Volume 1. Englewood Cliffs: Regents/ Prentice Hall 184-221.

5. Tanada N, Kageura M, Hara K, Hieda Y, Takamoto M, et al. (1991) Identification of human hair stained with oxidation hair dyes by gas chromatographic-mass spectrometric analysis. Forensic Sci Int 52: 5-11.

6. Brenner L, Squires PL, Garry M, Tumosa CS (1985) A measurement of human hair oxidation by Fourier transform infrared spectroscopy. J Forensic Sci 13: 420-26.

7. Wittig M (1982) Protein patterns of keratins-the probable role in forensic hair examination. J Forensic Sci Soc 22: $387-9$.

8. Hopkins J, Brenner L, Tumosa CS (1991) Variation of the Amide I and Amide II peak absorbance ratio in human hair as measured by Fourier transform infrared spectroscopy. Forensic Sci Int 50: 61-5.

9. Al-Hashimi A (1994) Trace elements in the hair of new-born infants by INAA. J Radioanal Nucl Chem 179: 357-64.

10. Pillay KKS, Kuis RL (1978) The potentials and limitations of using neutron activation activation analysis data on human hair as forensic evidence. J Radioanal Chem 43: 461-78.

11. Homan JA, Genoways HH (1978) An analysis of hair structure and its phylogenetic implications among heteromyid rodents. J Mamm 59: 740-60.

12. Lanning KA, Michaud AL, Bisbing RE, Springer FA, Tridico SR (2009) Scientific Working Group on Materials Analysis Position on Hair Evidence. J Forensic Sci 54: 1198-202.

13. Kaboudarahangi M, Tahir OM, Kamal MMS (2013) Malaysia’s Three Major Ethnic Group Preferences in Creating a Malaysian Garden Identity. Australian Geographer 44: 197-213.

14. Ogle RR, Fox MJ (1998) Atlas of human hair: Microscopic characteristics. CRC Press: 41-3.

15. Takahashi T, Hayashi R, Okamoto M, Inoue S (2006) Morphoghy and properties of Asian and Caucasian air. J Cosmet Sci 57: $327-38$.

16. Khan A, Maryam J, Yaqub T, Nadeem A (2014) Human hair analysis among four different castes having potential application in forensic investigation. J Forensic Res 5: 1-4.

17. Kaur G, Kumar M (2000) Medulla types of hair: a study of the Brahmin and Rajputs of the Punjab. J Human Ecol 11: 483-86.

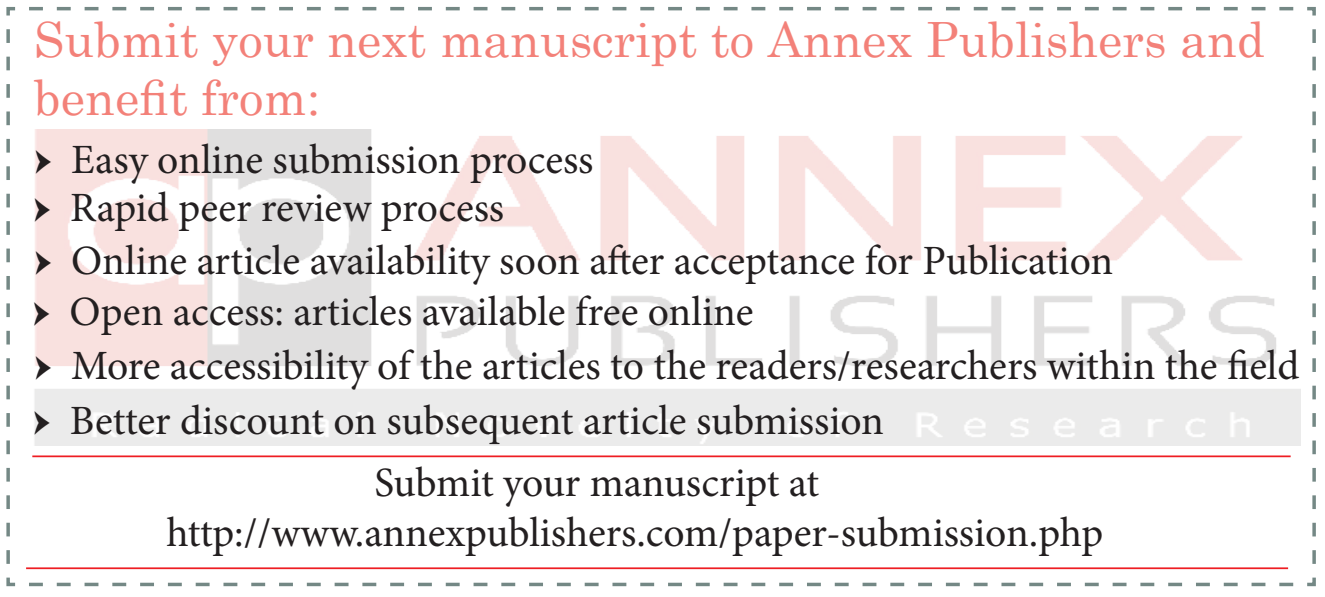

